\title{
Provinces weighing HPV vaccination of boys
}

$\mathrm{P}$ rovinces weighing the merits of implementing the National Advisory Committee on Immunization's recommendation to offer human papillomavirus (HPV) vaccine to boys and men aged 9-26 are facing a tricky trade-off between benefits and costs.

"I think the benefits are there, but the costs are high," which is a crucial issue for publicly-funded programs, says Dr. Monika Naus, medical director of immunization programs and vaccine-preventable diseases for the British Columbia Centre for Disease Control.

Earlier this year, the National Advisory Committee on Immunization recommended extending the human papillomavirus vaccine to boys and men aged 9-26 "for the prevention of anal intraepithelial neoplasia (AIN) grades 1,2 , and 3, anal cancer, and anogenital warts" (www.phac-aspc.gc.ca/publicat /ccdr-rmtc/11vol37/acs-dcc-8/index-eng .php\#a5). The move followed on the heels of an October 2011 recommendation from United States Centers for Disease Control and Prevention advisory panel recommendation that HPV vaccine be given to boys aged $11-12$ to ward off genital warts, anal cancer and "possibly" head and neck cancer (www .cdc.gov/media/releases/2011/t1025_hpv _12yroldvaccine.html).

In deciding whether to proceed, the provinces should note that "the public health and economic burden of AGWs [anogenital warts] in Canada is considerable, particularly among men whose incidence rates and incidence rate ratios compared to females have been increasing in recent years," the committee stated.

The committee's report also noted that the number of annual cases (and average annual incidence per 100 000) of penile cancer among men in Canada is 127.4 (1.0 per 100000$)$, while the rate for cancer of the anus is 208.2 (1.6), oral cavity 853.1 (6.5) and oropharynx 84.3 (0.64). The estimated portion of those cancers that are attributable to HPV is

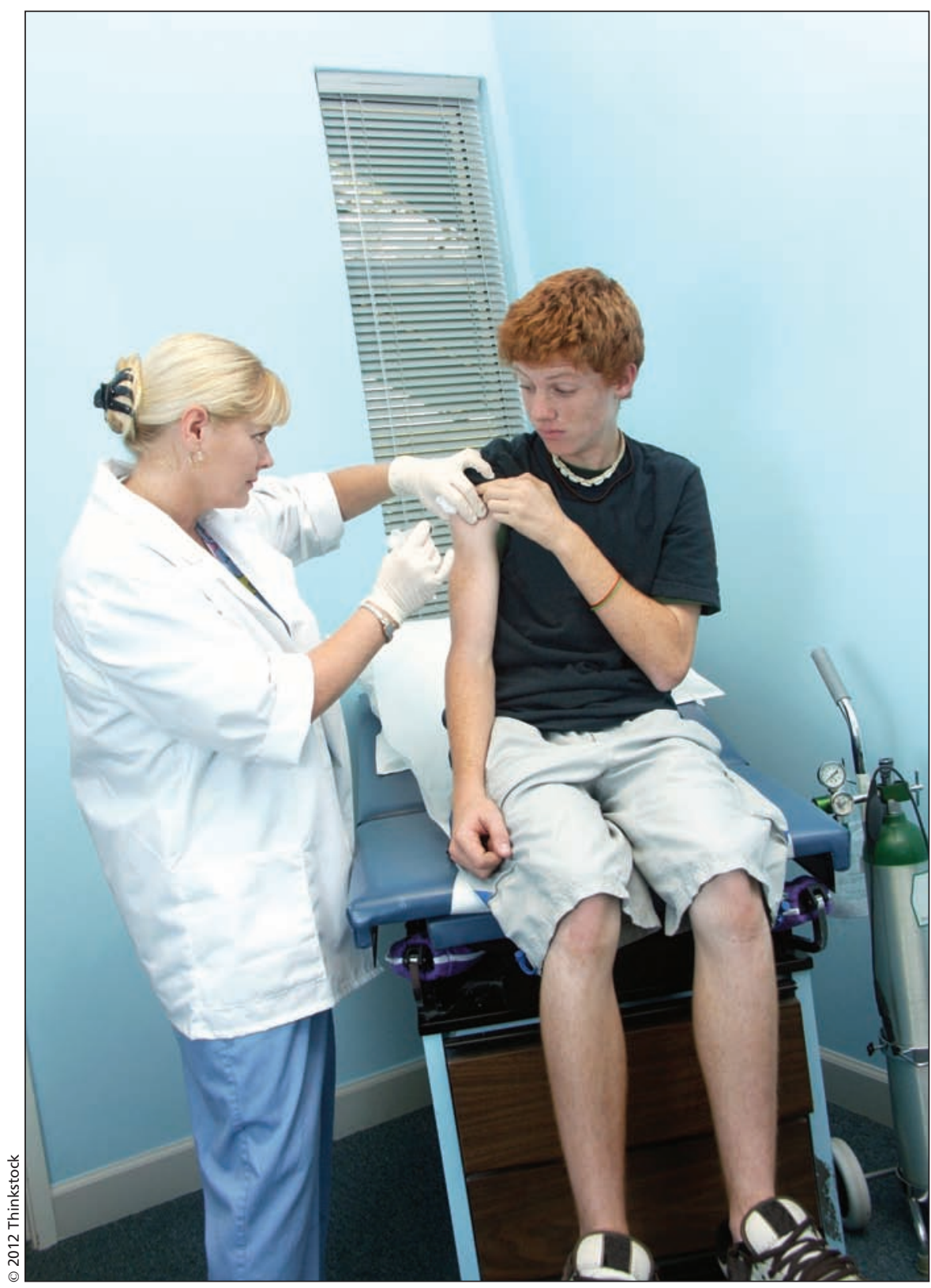

The National Advisory Committee on Immunization says provincial governments should weigh whether a human papillomavirus vaccination program for boys is preferable to campaigns designed to increase female vaccination rates.

$63 \%$ for penal cancer, $92 \%$ for anal cancer and $89 \%$ for both oral cavity and orapharygeal cancer.

The committee also advised that the provinces weigh whether an HPV vaccination program for boys is preferable to campaigns designed to increase female vaccination rates.
It also cautioned provinces against making the presumption that vaccinating boys would lower cervical cancer rates among girls. "While current models predict that addition of males to a routine HPV vaccination program would prevent additional cases of genital warts and cervical cancer among 
females to varying degrees, this is based on assumptions that such transmission from males to females will be reduced, rather than observational data."

Data on the economic burden of HPV is often highly conditional on a series of assumptions. The Canadian Consensus Guidelines on Human Papillomavirus issued by the Society of Obstetricians and Gynaecologists of Canada in 2007 projected the annual economic burden at $\$ 300$ million, with the bulk of that - $\$ 244$ million - representing the cost of "more than 9.3 million Pap tests that produce negative or false-positive results; the rest (\$53.7 million) is due to true genital or cervical disease. HPV types $6,11,16$, and 18 are thought to be responsible for $100 \%$ of the cost of genital warts $(\$ 9.2$ million), $36 \%$ of the cost of CIN 1 [cervical intraepithelial neoplasia] (total cost $\$ 15.7$ million), $61 \%$ of the cost of CIN 2/3 (total cost $\$ 14.5$ million), and $73 \%$ of the cost of cervical cancer (total cost \$13.6)," (www.hpvinfo.ca/uploads /hpvinfo.previewsite.ca/files/hpv-guide line-full_e.pdf).

The cost of a three-dose HPV vaccination, meanwhile, is generally projected to be in the neighbourhood of $\$ 450-\$ 500$.

That can quickly add up, as evidenced by the decision to vaccinate girls aged 11-14, which in 2007 resulted in a federal government allocation of $\$ 300$ million over three years.

Whether the federal government might provide a similar chunk of funds to vaccinate boys is unknown, says Dr. John Spika, director general of the Public Health Agency of Canada's Centre for Immunization and Respiratory Infectious Diseases.

Naus notes that lower incidence rates of oral, anal and penile cancer, as compared with cervical cancer, make it much harder to justify the outlay of tax dollars for a generalized campaign for boys. She also indicated the provinces are awaiting the findings of a Public Health Agency of Canada commissioned cost-benefit analysis of HPV vaccination of boys expected to be completed this spring.

The provinces must also grapple with the advisory committee's precaution that a program for boys must be weighed against measures designed to increase vaccination take-up by girls.

The Federation of Medical Women of Canada argues that vaccinating boys makes sense when there is a low uptake among girls, so it urges gender equity in the funding of HPV vaccination.

If a province has less than an $85 \%$ uptake among girls, there is a benefit to immunizing both sexes, says Dr. Vivien Brown, a member of the federation's board. "You cannot eradicate disease by simply vaccinating one sex," Brown says. "We don't have fantastic uptake of vaccine in women."

Naus notes that the vaccination rate among eligible girls in $\mathrm{BC}$ is now $70 \%$ and climbing annually at a rate of 5\%.
But Brown notes the rate is only 55\% in Ontario.

The provincial government is awaiting advice from Public Health Ontario before deciding whether to provide HPV vaccination of boys, says David Jensen, a spokesman for the province's Ministry of Health and Long-Term Care, while Quebec is awaiting advice from its public health institute, says Stephanie Menard, a spokesperson for the Quebec Ministry of Health and Social Services.

Spika says another major consideration is whether the intent of a vaccination program will be to prevent only HPVrelated cancers, or all HPV infections.

Both the Canadian and US advisory panels recommended against the use of one of those vaccines (Cervarix) for boys, on the grounds that its efficacy has not yet been proven.

Cervarix is not yet approved in Canada for use in boys but if it does become available and a province chooses to target only cancer-causing strains of HPV, that might reduce costs, Spika says. "Obviously, it's a competitive process, and having two products on the market is better than one."

No decisions are expected to be taken by provinces until the Canadian Immunization Committee, which represents provincial governments, finalizes its position on the issue. - Laura Eggertson, Ottawa, Ont.

CMAJ 2012. DOI:10.1503/cmaj.109-4140 